\title{
Molecular markers for novel therapies in neuroendocrine (carcinoid) tumors
}

\author{
Judith A Gilbert ${ }^{1 *}$, Laura J Adhikari ${ }^{2 \star}$, Ricardo V Lloyd $^{2}$, Joseph Rubin ${ }^{3}$, \\ Paul Haluska ${ }^{3}$, Joan M Carboni ${ }^{4}$, Marco M Gottardis ${ }^{4}$ and Matthew M Ames ${ }^{1}$
}

\author{
${ }^{1}$ Department of Molecular Pharmacology and Experimental Therapeutics, ${ }^{2}$ Department of Laboratory Medicine and Pathology, \\ ${ }^{3}$ Department of Oncology, Mayo Clinic, 200 First Street SW, Rochester, Minnesota 55905, USA \\ ${ }^{4}$ Oncology Drug Discovery, Bristol-Myers Squibb, Princeton, New Jersey 08543, USA \\ (Correspondence should be addressed to M M Ames; Email: ames.matthew@mayo.edu) \\ *(J A Gilbert and L J Adhikari contributed equally to this work)
}

\begin{abstract}
Neuroendocrine (carcinoid) tumors (NETs) are endocrine neoplasms occurring most frequently in gastrointestinal and bronchopulmonary (BP) systems. The majority of patients present with advanced disease for which few treatment options exist. We assessed 104 NETs (74 cases) for biomarkers targeted by anticancer drugs under development for other forms of cancer. Activating mutations were assessed in epidermal growth factor receptor (EGFR), stem cell factor receptor $(K I T)$, and platelet-derived growth factor receptor alpha (PDGFRA), as well as non-response mutations in KRAS. Copy number of EGFR and HER-2/neu was quantified with fluorescence in situ hybridization. Immunohistochemical analyses were performed for EGFR, KIT, PDGFRA, somatostatin receptor subtypes $2 \mathrm{~A}$ and 5 (SSTR5), vascular endothelial growth factor receptor 1 , mammalian target of rapamycin (mTOR), insulin-like growth factor 1 receptor (IGF1R), heat shock protein 90 (Hsp90), and transforming growth factor- $\beta$ receptor 1 (TGFBR1). NETs lacked HER2-overexpression predictive of anti-HER2 response and KIT and PDGFRA activating mutations indicative of imatinib sensitivity. High EGFR aneusomy ( $20 \%$ of all cases) and elevated EGFR copy number (39\%) were found, but few KRAS mutations associated with non-response to anti-EGFR therapy (3\%). Hsp90, TGFBR1, IGF1R, and SSTR5 exhibited highest levels of immunohistochemical staining in the largest percents of tumors. In subsequent in vitro studies, anticancer drug 17-(allylamino)-17-demethoxygeldanamycin (17-AAG) (targeting Hsp90) inhibited proliferation of $\mathrm{BP} \mathrm{NET}$ lines $\mathrm{NCl}-\mathrm{H} 727, \mathrm{NCl}-\mathrm{H} 720$, and $\mathrm{NCl}-\mathrm{H} 835$ with $\mathrm{IC}_{50}$ values of 70.4, 310, and $788 \mathrm{nM}$ respectively; BMS-754807 (targeting IGF1R/IR) inhibited growth with $\mathrm{IC}_{50}$ values of $428 \mathrm{nM}, 2.8 \mu \mathrm{M}$, and $1 \mu \mathrm{M}$. At growth-inhibiting concentrations, 17-AAG (24 h) induced loss of EGFR and IGF1R in the IGF1R-expressing NCl-H727 line, and BMS-754807 (24 h) inhibited constitutive IGF1R autophosphorylation. Our results support further research into Hsp90, IGF1R, and EGFR as targets for developing new anticancer therapeutics for some NETs.
\end{abstract}

Endocrine-Related Cancer (2010) 17 623-636

\section{Introduction}

Neuroendocrine (carcinoid) tumors (NETs) are neoplasms of the endocrine system arising predominantly in the gastrointestinal (GI) tract and respiratory system. These neoplasms originate in cells of the diffuse neuroendocrine system, and as a group display a heterogeneity related to the diversity of the sites of origin, e.g. the endocrine cells of the GI tract, the enterochromaffin-like cells of the stomach, the
Kulchitsky cells of the bronchopulmonary (BP) system. Neuroendocrine tumors characteristically overproduce biogenic amines and polypeptide hormones, with the result that advanced disease is frequently manifested clinically by the carcinoid syndrome. Surgery can be curative for small lesions, but the majority of neuroendocrine tumors are indolent and patients often present with advanced disease for which effective treatment options are limited. 
NETs, long understood to express neuroendocrine biomarkers and to produce polypeptide hormones, have more recently become known for expression of several growth factor proteins (see review of Schnirer et al. (2003)). In recent years of rationally designed anticancer therapies, protein kinase inhibitors and/or antibodies directed toward growth factor receptors and downstream effectors and regulators have been under development for other forms of cancer. Targets of these new inhibitor/antibody chemotherapeutic pharmaceuticals that might play a role in the biology of neuroendocrine tumors were therefore assessed in a collection of 104 NETs that included six primary and seven metastatic tissue sites ( 74 cases) to evaluate their potential as biomarkers for novel therapies in these neoplasms.

Genetic abnormalities in epidermal growth factor receptor (EGFR), KRAS, HER-2/neu, platelet-derived growth factor receptor alpha (PDGFRA), and stem cell factor receptor (KIT) were assessed in neuroendocrine tumors to identify biomarkers with potential for indicating response of these neoplasms to chemotherapeutics developed against those targets in other cancers. Mutations in EGFR exons 18, 19, and 21 are associated in non-small-cell lung cancer (NSCLC) with response to the tyrosine kinase inhibitor (TKI) gefitinib (Lynch et al. 2004, Paez et al. 2004), whereas high $E G F R$ copy number, determined by fluorescence in situ hybridization (FISH), is associated with sensitivity to gefitinib in NSCLC (Cappuzzo et al. 2005a, Hirsch et al. 2005) and to monoclonal antibodies cetuximab and panitumumab in colorectal cancer (Moroni et al. 2005, Sartore-Bianchi et al. 2007, Cappuzzo et al. 2008). In this study, activating mutations and FISH-determined copy number of EGFR (a protein expressed in $91 \%$ of GI neuroendocrine tumor primaries as well as $98 \%$ of metastases (Papouchado et al. 2005)) were investigated as markers for response to anti-EGFR inhibitors and antibodies. Mutations in KRAS codons 12 and 13 are associated with lack of response to cetuximab (Lievre et al. 2006, De Roock et al. 2008, Karapetis et al. 2008) and panitumumab (Amado et al. 2008) in colorectal cancer, and to TKIs gefitinib and erlotinib in lung cancer (Eberhard et al. 2005, Pao et al. 2005, Massarelli et al . 2007); therefore, KRAS mutations associated with nonresponse to anti-EGFR therapy were also assessed in NETs. High gene copy number of EGFR family member HER2 predicts response to monoclonal antibody trastuzumab in breast cancer (Perez et al. 2002); thus, HER-2/neu copy number analysis by FISH was employed to explore HER2-overexpression in neuroendocrine tumors as a biomarker for sensitivity to
anti-HER2 therapy. Finally, mutations in KIT exons 9, 11, 13, and 17 (Heinrich et al. 2003) and in PDGFRA exons 12, 14, and 18 (Corless et al. 2005) are associated with response of the gastrointestinal stromal tumor (GIST) to the TKI imatinib; as PDGFRA expression in neuroendocrine tumors is established (Schnirer et al. 2003), the mutational analyses of PDGFRA and KIT in these neoplasms were undertaken as predictors of imatinib effectiveness.

Immunohistochemical studies were performed to measure the expression levels of growth factor receptors and downstream effectors and regulators more recently developed as targets of anticancer drugs in other cancers, to assess their potential for indicating sensitivity in NETs. Neuroendocrine tumors exhibit vascular endothelial growth factor (VEGF) expression as well as transforming growth factor (TGF) secretion (Schnirer et al. 2003), leading us to examine VEGF receptor 1 (VEGFR1 or FLT1) immunohistochemistry (IHC) for appraising the potential of anti-angiogenesis therapy in these malignancies and TGF- $\beta$ receptor 1 (TGFBR1) expression for assessing the possibilities of anti-TGFBR1 kinase inhibitors. Furthermore, in an Affymetrix (Santa Clara, CA, USA) GeneChip (Human Genome U133A) microarray analysis that compared differences in gene expression between indolent and aggressive neuroendocrine neoplasms (five pairs), $\geq 2$-fold up-regulation was found in four of five aggressive NETs for Hsp90 alpha, insulin-like growth factor binding protein 2 , and the mammalian target of rapamycin (mTOR) substrate eukaryotic translation initiation factor $4 \mathrm{E}$ binding protein 1 (J A Gilbert, J Rubin \& M M Ames 2002, unpublished observations). Therefore, expression of heat shock protein 90 (Hsp90), insulin-like growth factor 1 receptor (IGF1R), and mTOR was explored using immunohistochemical analysis in neuroendocrine tumors to allow further evaluation in these neoplasms of the role for recently developed anticancer inhibitors/antibodies targeting these proteins.

Finally, follow-up in vitro studies were performed in three commercially available neuroendocrine tumor cell lines (BP origin) with chemotherapeutics targeting IGF1R and Hsp90, two strongly expressed biomarkers identified immunohistochemically in all neuroendocrine tumors. The effect of anticancer drugs 17-(allylamino)-17-demethoxygeldanamycin (17-AAG) (selective for Hsp90) and BMS-754807 (a dual inhibitor selective for IGF1R/IR) on cellular proliferation and biomarker functionality was measured.

We report here the results of a multifaceted approach (including mutational, gene copy number, immunohistochemical, and in vitro analyses) for 
assessing recently developed targets of anticancer therapeutics for their relevance in a heterogeneous collection of neuroendocrine tumors. This work was presented in preliminary form at the 100th Annual Meeting of the American Association for Cancer Research in April 2009 (Gilbert et al. 2009).

\section{Materials and methods}

\section{Patient samples}

Seventy-four cases with NETs (carcinoid tumors) associated with a variety of sites were identified at Mayo Clinic Rochester, with pathology slides accessible for review as well as with both formalin-fixed, paraffin-embedded tumor blocks and flash-frozen surgical specimens available for analyses. Prior to inclusion of a case in this study, a hematoxylin and eosin (H\&E) stained slide from each paraffinembedded tissue block associated with the case was reviewed by a pathologist ( $\mathrm{R} \mathrm{V} \mathrm{L)} \mathrm{to} \mathrm{confirm} \mathrm{the}$ diagnosis of neuroendocrine tumor. Written research authorization was obtained from all patients for this study, in addition to Mayo Clinic Institutional Review Board approval.

\section{Tissue microarray construction}

A tissue microarray (TMA) was constructed by the Tissue and Cell Molecular Analysis Shared Resource, Mayo Clinic Rochester, with a Beecher ATA-27 automated arrayer (Sun Prairie, WI, USA). From the 74 cases, 104 NETs were selected for study from six primary and seven metastatic tissue sites. The most characteristic area from each individual NET was circled on an H\&E slide, and triplicate $0.6 \mathrm{~mm}$ cores were removed from the corresponding area of tissue in the associated formalin-fixed, paraffin-embedded tumor block and were placed into a single recipient paraffin block. All tumor tissues included in construction of the TMA are listed, by case, in Supplementary Table S1 (see section on supplementary data given at the end of this article).

\section{Immunohistochemical analysis}

Sections $(5 \mu)$ of the NET TMA were analyzed by IHC for EGFR, KIT, PDGFRA, VEGFR1, mTOR, IGF1R, Hsp90, TGFBR1, and somatostatin receptor subtypes 2A (SSTR2A) and 5 (SSTR5). Immunohistochemical staining was performed on TMA sections by the Tissue and Cell Molecular Analysis Shared Resource, Mayo Clinic Rochester. Negative controls were prepared by substituting diluent for primary antibodies. IHC of all biomarkers was scored based on intensity from 0 to 3 by a single reviewer ( $\mathrm{L} \mathrm{J} \mathrm{A}$ ) and reviewed by another pathologist ( $\mathrm{R} \mathrm{V} \mathrm{L),} \mathrm{with} 0$ indicating absence of staining, and 1, 2, and 3 representing weak, moderate, and strong staining intensity respectively. The immunohistochemical intensity score reported for the staining of tumor cells within each assessable NET sample was the average from the replicate TMA cores for that tissue. Because progenitor cells of NETs belong to the diffuse neuroendocrine system, easily accessible normal tissue of origin for use in direct comparisons of tumor immunohistochemical staining was not readily available. All IHC antibodies and epitope retrieval methods are listed in Supplementary Table S2 (see section on supplementary data given at the end of this article).

\section{FISH analysis of gene copy number}

NET TMA sections $(5 \mu)$ were analyzed by FISH for EGFR and HER-2/neu copy number by the Cytogenetics Shared Resource Laboratory, Mayo Clinic Rochester, as reported (Gilbert et al. 2008). Thirty nuclei were scored per sample with quantitation of red signals (HER-2/neu or EGFR) and green signals (chromosome 17 centromere (CEP17) or chromosome 7 centromere (CEP7) respectively). A ratio of HER-2/neu:CEP17 or EGFR:CEP7 of $0.8-1.30$ was defined as normal, $<0.8$ was interpreted as gene deletion, 1.30-2.0 was defined as gene duplication, and $\geq 2.0$ was interpreted as gene amplification. Aneusomy was defined as a normal HER-2/neu:CEP17 or EGFR:CEP7 ratio with $>30 \%$ of cells having $\geq 3$ CEP17 or CEP7 signals respectively (i.e. a balanced gain in the number of gene copies and the number of chromosome copies). Aneuploid tumors were examined for the mean EGFR copy number/cell to determine whether $E G F R$ copy number was elevated ( $\geq 2.47 /$ nucleus (Sartore-Bianchi et al. 2007) or $\geq 2.92 /$ cell (Cappuzzo et al. 2008)). HER-2/neu and EGFR FISH-positive samples were defined to be those demonstrating amplification or high aneusomy with $\geq 40 \%$ of cells having $\geq 4$ copies of HER-2/neu or $E G F R$ respectively. Owing to the inherent admixture of tumor and non-tumor cells within the neuroendocrine tumors, the FISH-positivity for HER-2/neu and $E G F R$ as well as the FISH-determined elevation of $E G F R$ copy number/cell for each assessable neoplasm was assigned the highest value score from the replicate TMA cores for that sample. 


\section{Mutational analysis of selected EGFR, KIT, PDGFRA, and KRAS exons}

One hundred and two NET surgical specimens from the 74 cases in this study were flash frozen following excision and stored at $-70{ }^{\circ} \mathrm{C}$. DNA was isolated from frozen tumor samples with the QIAamp DNA Mini Kit (Qiagen), and employed for mutational analysis following amplification by the PCR. All neuroendocrine tumor tissues assessed for EGFR, KIT, PDGFRA, and KRAS mutations are listed, by case, in Supplementary Table S1. Mutational analyses of EGFR (exons 18, 19, and 21) were performed as previously described (Gilbert et al. 2005); KIT mutational analyses (exons 9,11, 13, and 17) were conducted as reported (Gilbert et al. 2008).

Mutational analyses of KRAS (exon 2) and PDGFRA (exons 12,14, and 18) were performed following PCR with PerfeCTa qPCR SuperMix (Quanta Biosciences, Gaithersburg, MD, USA) for KRAS and with iQ Supermix (Bio-Rad) with 1.25 units, final, of iTaq DNA Polymerase (Bio-Rad) for PDGFRA. The PCR primers and annealing temperatures for PDGFRA and $K R A S$ are listed in Supplementary Table S3 (see section on supplementary data given at the end of this article). PCR amplifications were done in a PerkinElmer (Foster City, CA, USA) model 9700 thermal cycler, and amplicons were sequenced on both strands by the DNA Sequencing Core, Mayo Clinic Rochester, using the universal M13 forward and reverse sequences as primers. ABI (Foster City, CA, USA) BigDye Terminator sequencing chemistry was used with an ABI 3730 DNA sequencer, and sequencing chromatograms were analyzed with Sequencher 4.8 (Gene Codes Corporation, Ann Arbor, MI, USA). Independent amplifications, followed by sequencing, were performed for all polymorphisms and mutations observed. GenBank accession numbers for the PDGFRA reference sequences used in this study were NT_022853.14 and NM_006206.3, whereas NG_007524.1 and NM_004985.3 were the reference sequences employed for KRAS.

\section{Cell culture}

The NCI-H727 (monolayer), NCI-H720 (suspension), and NCI-H835 (suspension) BP NET (carcinoid) cell lines were purchased from American Type Culture Collection (Manasses, VA, USA). Cell lines were cultured at $37{ }^{\circ} \mathrm{C}$ in a humidified environment of 95\%:5\% air: $\mathrm{CO}_{2}$ in RPMI 1640 (Invitrogen) supplemented with $10 \% \mathrm{v} / \mathrm{v}$ heat-inactivated fetal bovine serum (PAA Labs, New Bedford, MA, USA).

\section{Cell proliferation assay}

NCI-H727 (4000/well), NCI-H720 (20 000/well), or NCI-H835 (50 000/well) BP NET cells were seeded into 96-well plates (Corning, Corning, NY, USA) in $100 \mu \mathrm{l}$ aliquots of growth medium, and incubated at $37^{\circ} \mathrm{C}$ for $48 \mathrm{~h}$. Each drug concentration was added in $100 \mu \mathrm{l}$ of growth medium containing $0.125 \% \mathrm{v} / \mathrm{v}$ DMSO to replicates of six wells; $100 \mu$ lof growth medium containing $0.125 \% \mathrm{v} / \mathrm{v}$ DMSO without drug was added to six wells of control cells. Following incubation at $37^{\circ} \mathrm{C}$ for 5 days (continuous drug exposure) for NCI-H727 cells (6 days for NCI-H720 and NCI-H835 cells), cell growth was determined with the 3-(4,5-dimethylthiazol-2-yl)-5-(3-carboxymethoxyphenyl)-2-(4-sulfophenyl)-2H-tetrazolium, inner salt (MTS) assay (Cory et al. 1991), by addition to each well of $40 \mu \mathrm{l}$ containing a $20: 1$ ratio of $2 \mathrm{mg} / \mathrm{ml}$ MTS (Promega) and $0.92 \mathrm{mg} / \mathrm{ml}$ phenazine methosulfate (Sigma). After incubation at $37^{\circ} \mathrm{C}$ for $2 \mathrm{~h}$, absorbance was measured at $490 \mathrm{~nm}$ on an MR5000 (Dynatech, Chantilly, VA, USA) or SpectraMax Plus $^{384}$ (Molecular Devices, Sunnyvale, CA, USA) microplate reader. Three dose-response experiments for each drug were performed with each cell line, with growth of treated cells at each drug concentration compared to proliferation of control cells. $\mathrm{IC}_{50}$ values were estimated with the Prism program (GraphPad, San Diego, CA, USA) by fitting the mean percent control values for each drug concentration to the best sigmoidal dose-response curve using non-linear least squares regression analysis. Anticancer drugs BMS754807 and 17-AAG were kindly provided by Dr Scott Kaufmann, Mayo Clinic Rochester, and the National Cancer Institute (Bethesda, MD, USA) respectively.

\section{Western immunoblot analysis}

Whole cell lysates were prepared from cultured BP NET cells using RIPA lysis buffer (Santa Cruz Biotechnology, Santa Cruz, CA, USA) according to the manufacturer's protocol; protein was quantitated with the DC Protein Assay (Bio-Rad) following the manufacturer's instructions. Samples for western blot analysis were loaded on the basis of protein concentration and subjected to electrophoresis on $10 \% \mathrm{w} / \mathrm{v}$ separating gels (Criterion XT, Bio-Rad). Following transfer to PVDF membranes (Bio-Rad), immunoreactive proteins were detected with SuperSignal West Pico Chemiluminescent Substrate (Pierce, Rockford, IL, USA) and HyBlot CL film (Denville Scientific, Metuchen, NJ, USA). Primary antibodies employed were anti-EGFR (Santa Cruz sc-03), antiIGF1R $\beta$ (Cell Signaling 3027; Danvers, MA, USA), 
anti-phospho-IGF1R $\beta$ (Tyr1131)/insulin receptor $\beta$ (Tyr1146) (Cell Signaling 3021), anti-Hsp90 (Cell Signaling 4874), and anti- $\beta$-actin (Santa Cruz sc-130656); the secondary antibody was goat anti-rabbit IgG-HRP (Santa Cruz sc-2004).

\section{Results}

\section{Patient cases}

Forty-two of the 74 patients in this study were females; 32 were males (Table 1). The median age at the time of this surgery was 60 years (range 24-80). The majority of patients (57) had metastatic or multicentric disease at surgery; of this subset, 19 patients had received a variety of treatments for carcinoid disease prior to this surgery (Table 2 lists these cases and the types of therapy). Patients presenting with solitary, nonmetastatic primaries at the time of surgery had BP (15) or appendiceal (2) neoplasms.

One hundred and four neuroendocrine tumors from these 74 cases were chosen for inclusion in the TMA construction, with equal numbers of primary and metastatic neoplasms (see Table 1). The BP system and small bowel were the most common primary tumor sites represented, with the liver being the most frequent metastatic tissue. Supplementary Table S1 lists all neuroendocrine tumor tissues, by case, included in the TMA.

Table 1 Patient characteristics (74 cases)

\begin{tabular}{ll}
\hline Sex & 32 \\
Male & 42 \\
Female & 60 years (24-80) \\
Median age (range) at surgery & \\
Year of surgery & 49 \\
1990-1999 & 25 \\
$2000-2009$ & 8 \\
History of other cancer & 57 \\
Metastatic/multicentric & 19 \\
Previous therapy & \\
Primary sites in TMA & \\
Lung & 22 \\
Small bowel & 18 \\
Colon & 5 \\
Appendix & 3 \\
Stomach & 3 \\
Pancreas & 1 \\
Metastatic sites in TMA & \\
Liver & 30 \\
Lymph node & 10 \\
Mesentery & 8 \\
Uterus & 1 \\
Ovary & 1 \\
Peritoneum & 1 \\
Rectum & \\
\hline
\end{tabular}

${ }^{\text {a Total of }} 104$ NET samples in TMA.

\section{Mutational analysis of EGFR, KIT, PDGFRA, and KRAS}

A total of 102 neuroendocrine tumors from the 74 cases in this study were analyzed for mutations in selected exons of EGFR, KIT, PDGFRA, and KRAS. Supplementary Table $\mathrm{S} 1$ lists all tumors, by case, subjected to mutational analysis; in $36 \%$ of cases, differing numbers of neuroendocrine tumor sites were available for mutational analysis as for TMA inclusion. However, for all but three of the 74 cases, a minimum of one tumor site per case was subjected to all assays: FISH and IHC assessments (via TMA inclusion) as well as mutational analyses.

\section{EGFR, KIT, and PDGFRA}

No EGFR mutations predictive of gefitinib sensitivity were found in any of the 102 neuroendocrine tumor sites analyzed (81 of these analyses had been previously reported (Gilbert et al. 2005)). Similarly, no KIT or PDGFRA mutations associated with clinical response to imatinib were detected in any neuroendocrine tumor.

Results of mutational analyses indicated that all neuroendocrine tumors assessed from all 74 patients carried the synonymous single nucleotide polymorphism (SNP) dbSNP rs1873778 in PDGFRA exon 12 (A1701G, where number ' 1 ' is assigned to the ' $\mathrm{A}$ ' in the translation initiation codon of the cDNA; amino acid position 567), with two cases being heterozygous and 72 cases being homozygous for this SNP. Tumors from $20 \%$ of the cases harbored the synonymous SNP dbSNP rs2228230 in PDGFRA exon 18 (C2472T; amino acid 824), with this polymorphism being heterozygous in 13 cases and homozygous in two cases.

\section{KRAS}

KRAS codon 12 mutations associated with nonresponse to anti-EGFR monoclonal antibodies (Lievre et al. 2006, Amado et al. 2008, De Roock et al. 2008, Karapetis et al. 2008) and TKIs (Eberhard et al. 2005, Pao et al. 2005, Massarelli et al. 2007) were identified in only two neuroendocrine tumors, both aggressive neoplasms: G35A (encoding G12D) in a colon primary from a patient with a survival period of 3 months following diagnosis, and G35T (encoding G12V) in an ovarian metastasis from a patient with a 2.3-year survival (Table 2 indicates the two tumors harboring $K R A S$ non-response mutations).

Mutational analysis of KRAS exon 2 detected the non-classical codon 18 mutation C53A (Morgan et al. 2001) (encoding amino acid substitution A18D) in one 


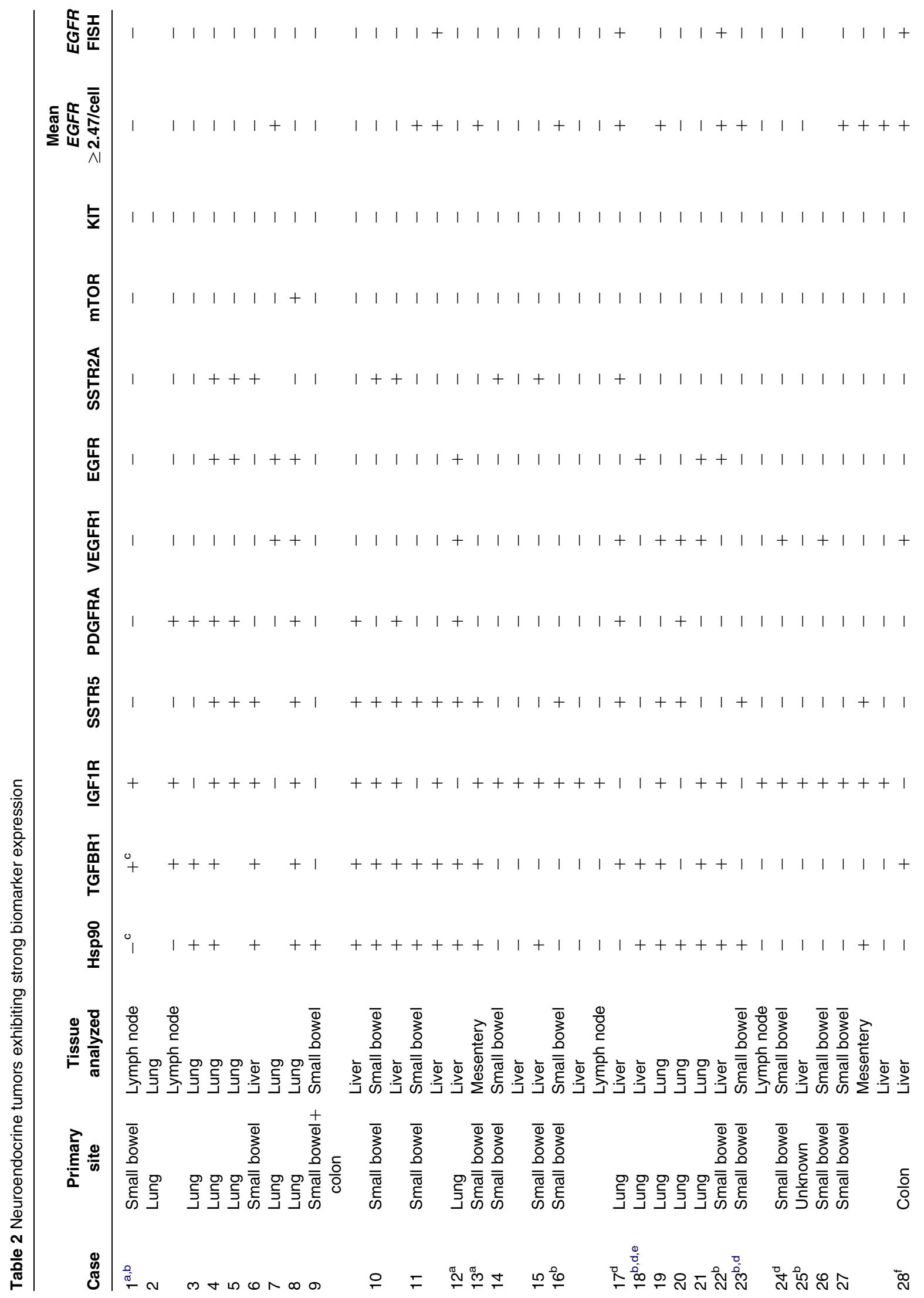




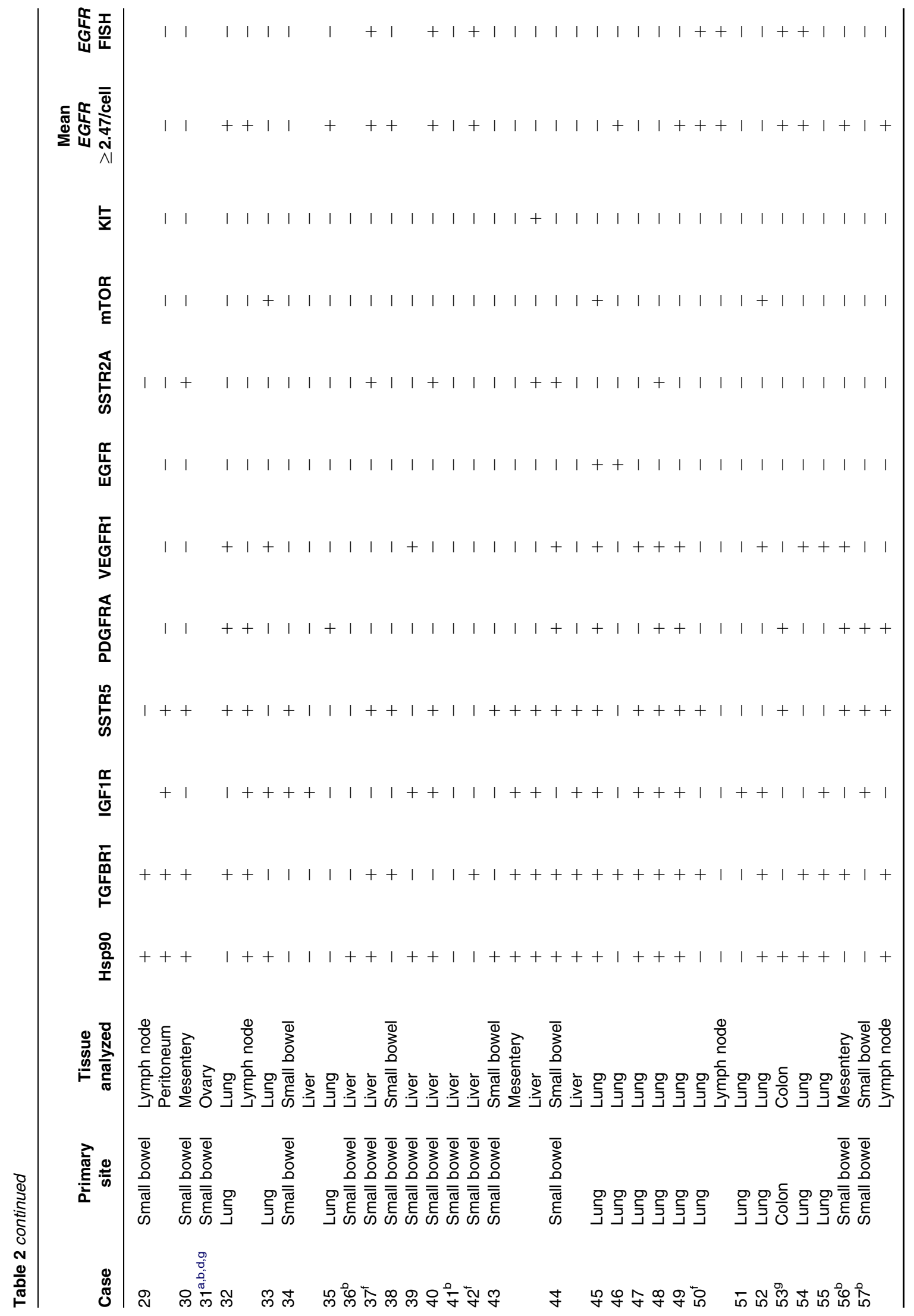




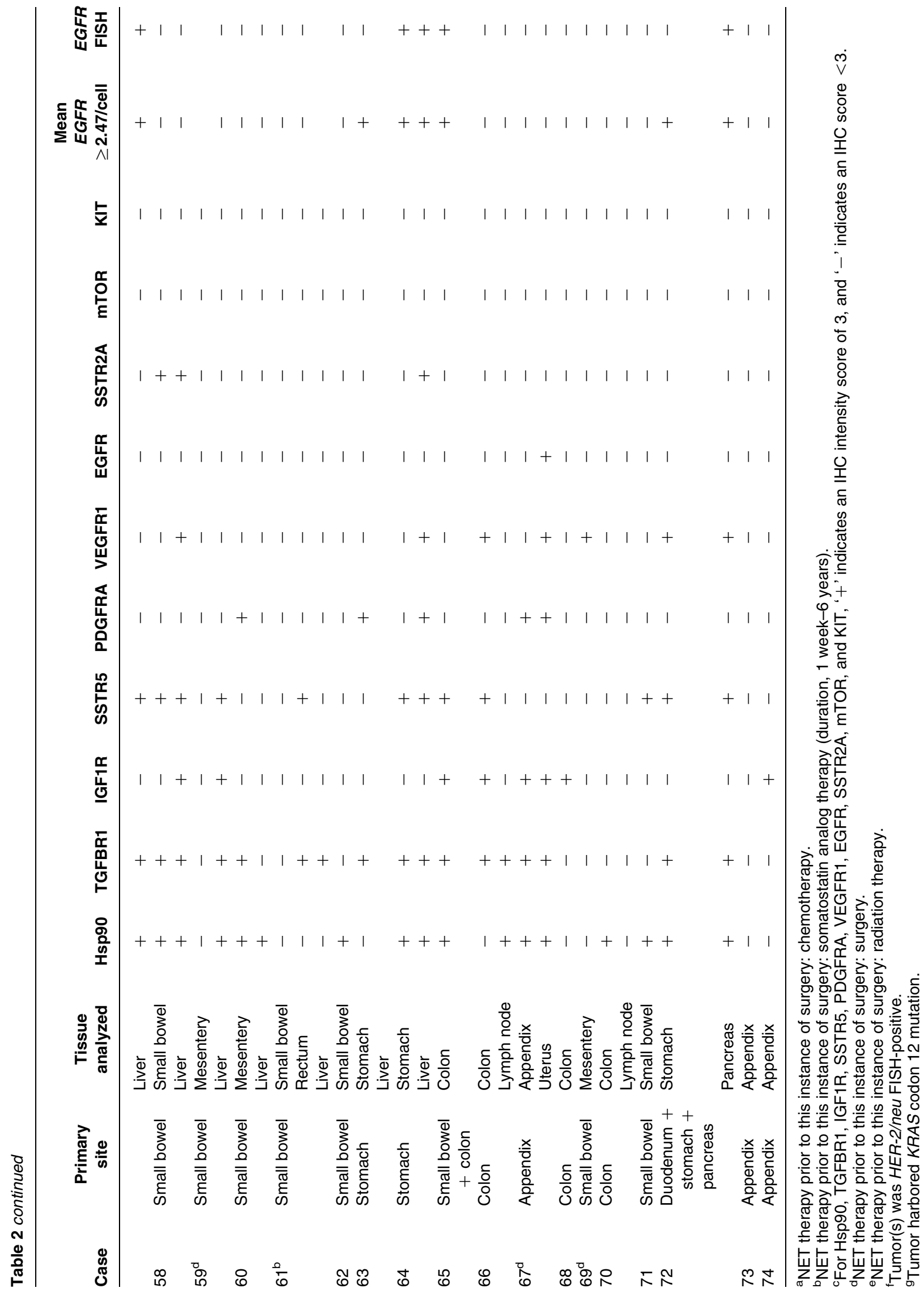


neuroendocrine tumor, a liver metastasis from an ileal primary lacking this mutation. All three KRAS mutations found in the neuroendocrine tumors were heterozygous.

\section{FISH analysis of EGFR and HER-2/neu copy number}

EGFR

FISH analyses detected that $39 \%$ of all assessable cases had neuroendocrine tumors displaying EGFR aneusomy with EGFR copy number at the elevated levels associated with sensitivity of colorectal cancer to panitumumab (mean copy number $\geq 2.47 /$ nucleus (Sartore-Bianchi et al. 2007)); 26\% exhibited aneusomy with elevated EGFR copy number predictive of cetuximab response (mean copy number $\geq 2.92 /$ cell (Cappuzzo et al. 2008)). Of the primary neuroendocrine tumors examined by FISH, those exhibiting elevated mean EGFR copy number ( $\geq 2.47 /$ nucleus) included $38 \%$ of the BP primaries and $29 \%$ of the small bowel primaries. Of 20 cases in which multiple tumor tissues from the same patient were assessable by FISH for elevated EGFR copy number, the primary and metastatic tumor(s) were both positive in five cases and both negative in ten patients, multiple primaries from different tissue sites were both positive in one case, multiple metastases from different sites were both negative in one case, the metastatic tumors but not the primary were positive in one case, and the primary but not the metastatic tumor(s) was positive in two cases. Table 2 indicates the neuroendocrine tumors with elevated EGFR copy number, on a case-by-case basis.

Fifty-two percent of cases with tumors displaying elevated EGFR copy number were also 'FISHpositive', exhibiting copy number at the high levels associated with gefitinib response (aneusomy with $\geq 40 \%$ of cells having $\geq 4$ copies of EGFR (Cappuzzo et al. 2005a, Hirsch et al. 2005)). Of these 14 patients (20\% of all assessable cases) exhibiting EGFR FISHpositive NETs, six were identified with FISH-positive primaries (two colon, two lung, one stomach, and one pancreas primary case - with one lung and one stomach primary tumor associated with a FISHpositive metastasis). Six cases had only (FISHpositive) liver metastases available for analysis (four originating in small bowel and one each from lung and colon). The remaining two cases had FISH-negative small bowel primaries with FISH-positive liver metastases (see Table 2 for a listing of EGFR FISHpositive tumors).

\section{HER-2/neu}

HER-2/neu aneusomy was detected in $21 \%$ of all assessable cases, but HER-2/neu copy number was below levels predictive of anti-HER 2 response (defined as $>6$ HER-2/neu copies/cell or a HER-2/neu:CEP17 ratio $>2.2$, by FISH analysis (Wolff et al. 2007)). However, four cases with HER-2/neu aneusomy exhibited high copy number for both $E G F R$ and HER-2/neu (aneusomy with $\geq 40 \%$ of cells having $\geq 4$ gene copies), a pairing predictive of gefitinib sensitivity greater than that for patients with high EGFR copy number alone (Cappuzzo et al. 2005b). Three of these four cases had only liver metastases available for analysis, one originating from an aggressive colon neoplasm and two from small bowel primaries (one multicentric); the fourth EGFR and HER-2/neu FISH-positive tumor was an atypical BP NET (associated with a FISH-positive lymph node). Table 2 indicates the HER-2/neu FISH-positive tumors.

\section{Immunohistochemical analysis}

Immunohistochemical staining in neuroendocrine tumors for EGFR, KIT, PDGFRA, SSTR2A, SSTR5, VEGFR1, mTOR, IGF1R, Hsp90, and TGFBR1 is illustrated in Fig. 1. The immunohistochemical staining intensity score for each assessable NET in the TMA is presented for each biomarker in Fig. 2, with scores grouped by location of malignancy into one of six large categories (three for primaries and three for metastases). The biomarkers for which the largest number of neuroendocrine tumors exhibited the strongest IHC staining were Hsp90, TGFBR1, IGF1R, and SSTR5, with intensity scores of 3 for 61 , 60,53 , and $51 \%$ of all neoplasms respectively. For the two most common primary sites studied, the percent of tumors which exhibited the highest Hsp90, TGFBR1, IGF1R, and SSTR5 score was 74, 79, 62, and 55\% of BP neoplasms respectively, and 50, 28, 44, and $61 \%$ of small bowel NETs. The biomarker with the lowest expression level by IHC was KIT, with complete absence of staining in $61 \%$ of all neuroendocrine tumors. For each immunohistochemical target protein studied, the staining intensity score averaged over all primaries was not significantly different from the score averaged over all metastases (data not shown) except for mTOR, whose average score was $1.85 \pm 0.08$ (mean \pm s.E.M.) for primaries and $1.44 \pm 0.10$ for metastases $(P<0.01)$.

Table 2 presents, by case, all assessable neuroendocrine tumors which exhibited strong immunohistochemical staining (intensity score of 3 ) for the ten molecular markers studied. Hsp90, TGFBR1, IGF1R, 

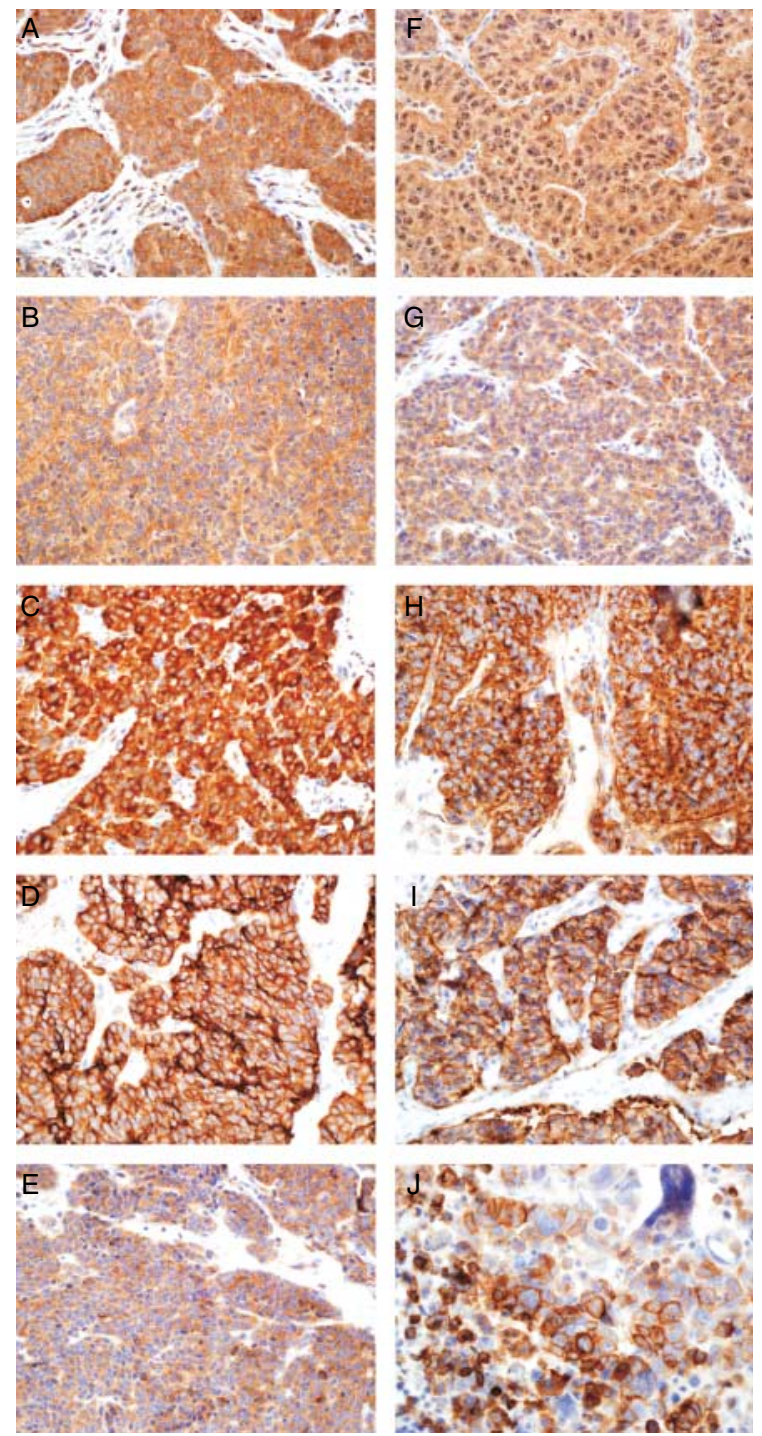

Figure $1 \mathrm{Immunohistochemical} \mathrm{analysis} \mathrm{of} \mathrm{neuroendocrine}$ tumors. Panels illustrate individual NET specimens in the TMA (original magnification $\times 200$ ) exhibiting strong immunostaining for (A) Hsp90, (B) IGF1R, (C) PDGFRA, (D) EGFR, (E) mTOR, (F) TGFBR1, (G) SSTR5, (H) VEGFR1, (I) SSTR2A, and (J) KIT.

and SSTR5 (the strongest staining biomarkers for the largest number of NETs) were expressed in all tumors from 20 cases in which primary and metastatic tumor tissues from the same patient were assessable. For the majority of these cases, tumors at all sites were consistent in expression of the four biomarkers, with all neoplasms exhibiting an IHC score of either 3 or $<3$. However, a difference in immunohistochemical staining levels between primary and metastatic tumor(s) from the same patient was seen for Hsp90, TGFBR1, IGF1R, and SSTR5 in 30, 25, 45, and $40 \%$ of these cases respectively.

\section{In vitro effects of anticancer drugs in neuroendocrine tumor cell lines}

Commercially available human neuroendocrine tumor lines were obtained for in vitro studies assessing the effect on NET cells of anticancer drugs targeting Hsp90 and IGF1R, two of the biomarkers found by IHC to be strongly expressed in all neuroendocrine tumors. Purchasable NET lines were all of BP origin, so NCI-H727, NCI-H720, and NCI-H835 cells were employed for our studies measuring the effect of chemotherapeutics on cell proliferation and biomarker functionality.

Western immunoblot analyses provided evidence that Hsp90 was ubiquitously expressed in all three lines (Fig. 3A). MTS assays measuring the effect of the chemotherapeutic agent 17-AAG (selective for Hsp90) on BP NET cell lines indicated that 17-AAG inhibited proliferation of NCI-H727, NCI-H720, and NCI-H835 cells with $\mathrm{IC}_{50}$ values of $70.4,310$, and $788 \mathrm{nM}$ respectively $(n=3)$.

Of the three cell lines, only NCI-H727 cells expressed IGF1R at levels detectable by western immunoblot analysis (Fig. 3A). MTS assays assessing the effect of anticancer therapeutic BMS-754807 (a dual inhibitor selective for IGF1R/IR) indicated that BMS-754807 inhibited proliferation of NCI-H727, NCI-H720, and NCI-H835 cells with $\mathrm{IC}_{50}$ values of $428 \mathrm{nM}, 2.8 \mu \mathrm{M}$, and $1 \mu \mathrm{M}$ respectively $(n=3)$.

$E G F R$ aneusomy was detected by FISH analyses in all three BP NET cell lines, with elevated EGFR copy number predictive of sensitivity to panitumumab and cetuximab; all three lines were also EGFR FISHpositive, exhibiting the high levels of EGFR aneusomy associated with gefitinib response. However, only NCIH727 cells expressed EGFR detectable by immunoblot analyses (Fig. 3A). Therefore, subsequent experiments with NET cells measuring by western analysis the downstream effects of anticancer drugs on EGFR and IGF1R expression, as well as on IGF1R function, were performed exclusively with the NCI-H727 line.

Incubation of NCI-H727 cells ( $24 \mathrm{~h}$ ) with 17-AAG concentrations ranging from 31 to $1000 \mathrm{nM}$ resulted in a dose-dependent decrease in the level of both IGF1R and EGFR as measured by western immunoblot analysis, with the more dramatic effect being observed on IGF1R $(n=3)$. Figure 3B illustrates in NCI-H727 cells the 17-AAG-induced dose-dependent decrease in cell proliferation and in cellular levels of EGFR and IGF1R. Exposure (24 h) of NCI-H727 cells to BMS754807 at concentrations from 0.3 to $10 \mu \mathrm{M}$ completely inhibited the constitutive autophosphorylation of IGF1R at all concentrations tested $(n=3)$. 

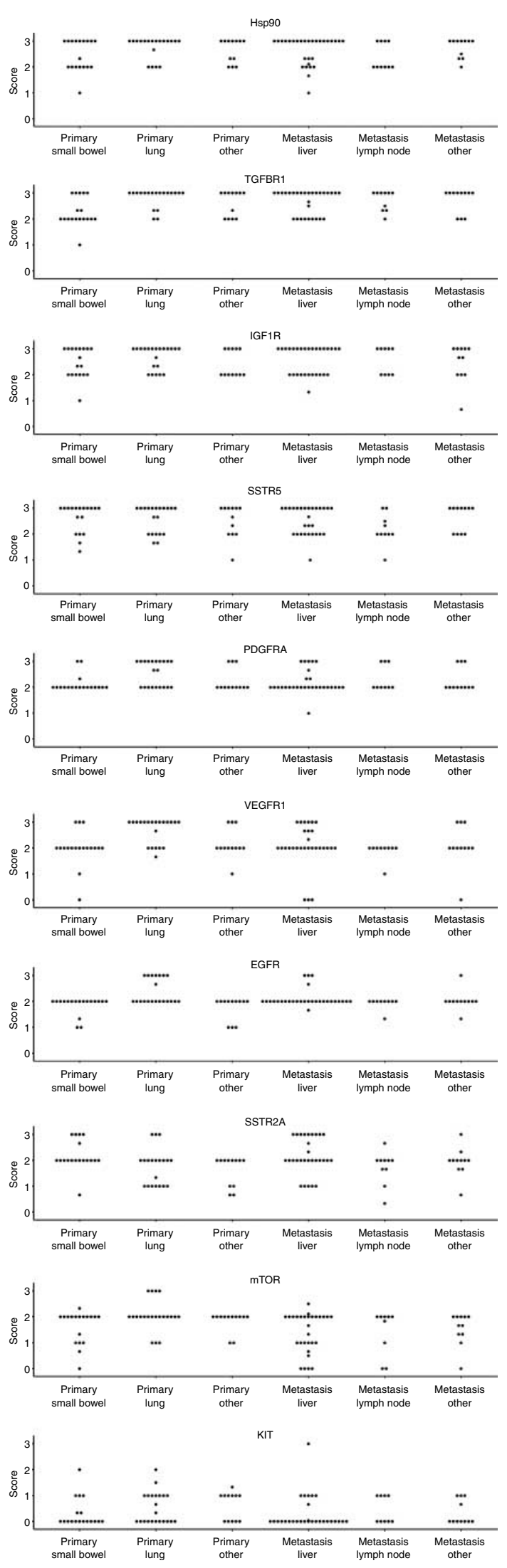

An illustration of the inhibition induced by increasing BMS-754807 concentrations on NCI-H727 cell proliferation as well as on constitutive IGF1R autophosphorylation is presented in Fig. 3C.

\section{Discussion}

While somatostatin therapy is effective for clinical symptoms associated with metastatic disease and may delay progression of disease, neuroendocrine tumors are often unresponsive to conventional chemotherapeutic regimens (see review of Schnirer et al. (2003)), and new drug therapies are needed. We analyzed a heterogeneous collection of NETs for genetic abnormalities as well as protein expression levels of a variety of growth factor receptors and downstream effectors and regulators targeted by anticancer drugs currently under development for other forms of cancer but whose natural ligands might also play a role in the biology of neuroendocrine tumors (see review of Schnirer et al. (2003)).

Mutational analyses detected neither EGFR mutations predictive of gefitinib sensitivity in any of the neuroendocrine tumors analyzed nor KIT or PDGFRA activating mutations predictive of imatinib response. Few KRAS mutations associated with nonresponse to anti-EGFR therapy were detected in NETs, occurring in only $3 \%$ of all cases.

FISH assays detected no HER2 overexpression predictive of trastuzumab response in any of these malignancies; however, four cases with high HER-2/neu copy number also exhibited high EGFR copy number, a pairing predictive of gefitinib sensitivity. Elevated EGFR copy number was detected by FISH in $39 \%$ of all assessable cases with high aneusomy exhibited by $20 \%$, although moderate EGFR expression levels were displayed immunohistochemically across all neuroendocrine tumors. Elevated EGFR copy number was demonstrated in both BP and GI primaries (38 vs 29\%), suggesting further research into the role of anti-EGFR TKIs and monoclonal antibodies in neuroendocrine tumors.

Protein expression levels of ten biomarkers were compared immunohistochemically, including those for SSTR2A and SSTR5. The moderate expression of SSTR2A (the long form of SSTR2) in this entire

Figure 2 Immunohistochemical staining intensity of neuroendocrine tumors for ten biomarkers. Individual IHC staining intensity scores for all NETs assessable in the TMA $(n=104)$ were grouped by tissue site into one of six large categories for comparison. Primary Other: colon, appendix, stomach, and pancreas primaries; Metastases Other: mesentery, uterus, ovary, peritoneum, and rectum metastases. 
A
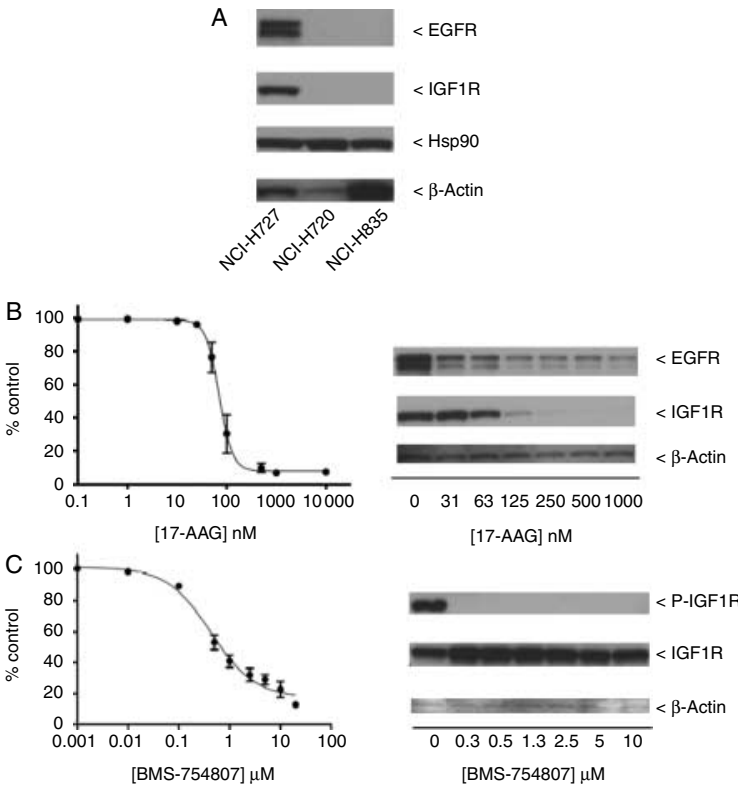

Figure 3 Effects of anticancer drugs in BP NET cell lines. (A) Whole cell lysates prepared from three BP NET cell lines ( $\mathrm{NCl}-\mathrm{H} 727, \mathrm{NCl}-\mathrm{H} 720$, and $\mathrm{NCl}-\mathrm{H} 835$ ) were analyzed by western immunoblotting for the presence of selected biomarkers. (B) Left: $\mathrm{NCl}-\mathrm{H} 727$ cells (4000/well) were incubated (continuous exposure, 5 days) in 96 -well plates at $37^{\circ} \mathrm{C}$ with increasing concentrations of the anticancer drug 17-AAG (targeting Hsp90) in serum-containing medium, with cell proliferation determined by the MTS assay; right: $\mathrm{NCl}-\mathrm{H} 727$ cells (500 000/well) were incubated (continuous exposure, $24 \mathrm{~h}$ ) in 6-well plates at $37^{\circ} \mathrm{C}$ with increasing concentrations of 17-AAG in serum-containing medium, with levels of indicated biomarkers analyzed by western immunoblotting of equal quantities of protein from whole cell lysates. (C) Effect of increasing concentrations of the anticancer drug BMS-754807 (targeting IGF1R/IR) on $\mathrm{NCl}-\mathrm{H} 727$ cell growth and constitutive IGF1R autophosphorylation, with experiments performed as described in (B). MTS data were the average \pm s.E.M. of three experiments; western immunoblotting results were representative blots from one of three experiments.

heterogeneous collection of neuroendocrine tumors, and, in particular, the high immunohistochemical levels of SSTR5, were consistent with the therapeutic importance of somatostatin analogs as inhibitory regulators of hormone hypersecretion responsible for clinical symptoms in advanced carcinoid disease. Of the five human somatostatin receptor subtypes (SSTR1-5), SSTR2 and SSTR5 have the highest binding affinity for somatostatin analogs employed clinically (primarily octreotide and lanreotide) (see review of Patel (1999)). Strong expression of somatostatin receptors on neuroendocrine tumors has long been correlated with symptomatic relief from the carcinoid syndrome in patients administered the somatostatin analog octreotide (Kvols et al. 1992, Modlin et al. 2010).
In marked contrast, KIT was not immunohistochemically expressed by the majority of neuroendocrine tumors. However, PDGFRA was moderately strongly expressed in all NETs, encouraging further study into the effect in these neoplasms of a PDGFRAspecific antibody like IMC-3G3 or anti-PDGFRA TKIs that are not dependent for activity upon the presence of activating mutations. mTOR was expressed weakly to moderately by most neuroendocrine tumors and was the only biomarker that exhibited different expression levels in primaries versus metastases (with higher expression in the former). In contrast, VEGFR1 was moderately strongly expressed in most neuroendocrine tumors, whereas Hsp90, TGFBR1, and IGF1R proteins were strongly expressed. While strong immunohistochemical staining was observed in a larger percent of BP than GI primaries for Hsp90 (74 vs 50\%) and IGF1R (62 vs 44\%), the high expression levels of these proteins in a large number of all neuroendocrine tumors encouraged follow-up in vitro studies of the effect on neuroendocrine tumor cells of anticancer drugs selective toward these biomarkers.

In experiments utilizing commercially available neuroendocrine tumor cells (three lines of BP origin), growth of the IGF1R-expressing NCI-H727 BP NET cells was inhibited by the anticancer drug BMS754807 (an anti-IGF1R/IR TKI currently in phase I clinical trials for treatment of solid tumors) at $\mathrm{nM}$ concentrations which completely inhibited constitutive IGF1R phosphorylation. Proliferation of the NCI-H720 and NCI-H835 lines (with IGF1R levels undetectable by western immunoblotting) was also inhibited by BMS-754807 albeit at high $(\mu \mathrm{M})$ concentrations, an effect possibly due to non-IGF1R-specific activity by the dual inhibitor BMS-754807. In addition, proliferation of all three Hsp90-expressing BP NET cell lines was sensitive to 17-AAG (an Hsp90 small molecule inhibitor currently in phase III clinical trials for treatment of multiple myeloma) at $\mathrm{nM}$ concentrations that also induced loss of cellular EGFR and IGF1R in the EGFR- and IGF1R-expressing NCI-H727 line. These results suggested that IGF1R and Hsp90 may be molecular biomarkers important for BP neuroendocrine tumor cell growth and might serve as the basis for further research into novel targeted therapeutics for these tumors.

Scientists and clinicians attending a September 2007 summit convened by the National Cancer Institute on gastroenteropancreatic neuroendocrine tumors concurred that one reason the mean overall survival of US patients with these tumors has not changed in 30 years is the lack of data on specific molecular targets for new therapies (Modlin et al. 2008). Our results here 
indicated that further study of new therapies for neuroendocrine tumors is warranted, e.g. presence of elevated EGFR copy number in $39 \%$ of all cases concomitant with infrequent occurrence of KRAS mutations suggests further analysis on the role of anti-EGFR monoclonal antibodies in these malignancies. In addition, strong immunohistochemical expression of ubiquitous molecular chaperone Hsp90 and of IGF1R in a majority of all neuroendocrine neoplasms is suggestive of additional research into the role that these two proteins play in neuroendocrine tumor growth; furthermore, growth inhibition of three BP NET lines by $17-\mathrm{AAG}$ and of IGF1R-expressing NCI-H727 cells by BMS-754807 at concentrations of the two chemotherapeutics which induced downstream biochemical effects in (EGFR- and IGF1R-expressing) NCI-H727 cells, is encouraging of further investigation into the therapeutic possibilities of targeting IGF1R and Hsp90 for development of novel anticancer drugs for, at a minimum, bronchopulmonary neuroendocrine tumors.

\section{Supplementary data}

This is linked to the online version of the paper at http://dx. doi.org/10.1677/ERC-09-0318.

\section{Declaration of interest}

The authors declare that there is no conflict of interest that could be perceived as prejudicing the impartiality of the research reported.

\section{Funding}

This research did not receive any specific grant from any funding agency in the public, commercial, or not-for-profit sector.

\section{Author contribution statement}

J A Gilbert and L J Adhikari, conception and design of study, acquisition and analysis of data, interpretation of results, drafting and critical editing of manuscript; R V Lloyd, conception and design of study, acquisition and analysis of data, interpretation of results, critical editing of manuscript; J Rubin, provision of medical perspective to study based on long-standing practice in the field of oncology, critical editing of manuscript; P Haluska, J M Carboni and M M Gottardis, provision of chemotherapeutic compound necessary for acquisition of data, critical review of manuscript based on long-standing expertise in the field of insulin-like growth factor targeting; M M Ames, conception of study, sponsoring of project, critical editing of manuscript.

\section{References}

Amado RG, Wolf M, Peeters M, Van Cutsem E, Siena S, Freeman DJ, Juan T, Sikorski R, Suggs S, Radinsky R et al. 2008 Wild-type KRAS is required for panitumumab efficacy in patients with metastatic colorectal cancer. Journal of Clinical Oncology 26 1626-1634.

Cappuzzo F, Hirsch FR, Rossi E, Bartolini S, Ceresoli GL, Bemis L, Haney J, Witta S, Danenberg K, Domenichini I et al. $2005 a$ Epidermal growth factor receptor gene and protein and gefitinib sensitivity in non-small-cell lung cancer. Journal of the National Cancer Institute 97 643-655.

Cappuzzo F, Varella-Garcia M, Shigematsu H, Domenichini I, Bartolini S, Ceresoli GL, Rossi E, Ludovini V, Gregorc V, Toschi L et al. $2005 b$ Increased HER2 gene copy number is associated with response to gefitinib therapy in epidermal growth factor receptor-positive non-small-cell lung cancer patients. Journal of Clinical Oncology 23 5007-5018.

Cappuzzo F, Finocchiaro G, Rossi E, Janne PA, Carnaghi C, Calandri C, Bencardino K, Ligorio C, Ciardiello F, Pressiani T et al. 2008 EGFR FISH assay predicts for response to cetuximab in chemotherapy refractory colorectal cancer patients. Annals of Oncology 19 717-723.

Corless CL, Schroeder A, Griffith D, Town A, McGreevey L, Harrell P, Shiraga S, Bainbridge T, Morich J \& Heinrich MC 2005 PDGFRA mutations in gastrointestinal stromal tumors: frequency, spectrum and in vitro sensitivity to imatinib. Journal of Clinical Oncology 23 5357-5364.

Cory AH, Owen TC, Barltrop JA \& Cory JG 1991 Use of an aqueous soluble tetrazolium/formazan assay for cell growth assays in culture. Cancer Communications $\mathbf{3}$ 207-212.

De Roock W, Piessevaux H, De Schutter J, Janssens M, De Hertogh G, Personeni N, Biesmans B, Van Laethem J-L, Peeters M, Humblet Y et al. 2008 KRAS wild-type state predicts survival and is associated to early radiological response in metastatic colorectal cancer treated with cetuximab. Annals of Oncology 19 508-515.

Eberhard DA, Johnson BE, Amler LC, Goddard AD, Heldens SL, Herbst RS, Ince WL, Janne PA, Januario T, Johnson DH et al. 2005 Mutations in the epidermal growth factor receptor and in KRAS are predictive and prognostic indicators in patients with non-small-cell lung cancer treated with chemotherapy alone and in combination with erlotinib. Journal of Clinical Oncology 23 5900-5909.

Gilbert JA, Lloyd RV \& Ames MM 2005 Lack of mutations in EGFR in gastroenteropancreatic neuroendocrine tumors. New England Journal of Medicine 353 209-210.

Gilbert JA, Goetz MP, Reynolds CA, Ingle JN, Giordano KF, Suman VJ, Blair HE, Jenkins RB, Lingle WL, Reinholz MM et al. 2008 Molecular analysis of metaplastic breast carcinoma: high EGFR copy number via aneusomy. Molecular Cancer Therapeutics 7 944-951. 
Gilbert JA, Adhikari LJ, Lloyd RV, Rubin J \& Ames MM 2009 Analysis of markers predictive for response in carcinoid tumors. Proceedings of the 100th Annual Meeting of the American Association for Cancer Research Abstr. No. 748.

Heinrich MC, Corless CL, Demetri GD, Blanke CD, von Mehren M, Joensuu H, McGreevey LS, Chen C-J, Ven den Abbeele AD, Druker BJ et al. 2003 Kinase mutations and imatinib response in patients with metastatic gastrointestinal stromal tumor. Journal of Clinical Oncology 21 4342-4349.

Hirsch FR, Varella-Garcia M, McCoy J, West H, Xavier AC, Gumerlock P, Bunn PA Jr, Franklin WA, Crowley J, Gandara DR et al. 2005 Increased epidermal growth factor receptor gene copy number detected by fluorescence in situ hybridization associates with increased sensitiviy to gefitinib in patients with bronchioloalveolar carcinoma subtypes: a Southwest Oncology Group study. Journal of Clinical Oncology 23 6838-6845.

Karapetis CS, Khambata-Ford S, Jonker DJ, O'Callaghan CJ, Dongsheng T, Tebbutt NC, Simes RJ, Chalchal H, Shapiro JD, Robitaille S et al. 2008 K-ras mutations and benefit from cetuximab in advanced colorectal cancer. New England Journal of Medicine 359 1757-1765.

Kvols LK, Reubi JC, Horisberger U, Moertel CG, Rubin J \& Charboneau JW 1992 The presence of somatostatin receptors in malignant neuroendocrine tumor tissue predicts responsiveness to octreotide. Yale Journal of Biology and Medicine 65 505-518.

Lievre A, Bachet J-B, Le Corre D, Boige V, Landi B, Emile J-F, Cote J-F, Tomasic G, Penna C, Ducreux M et al. 2006 KRAS mutation status is predictive of response to cetuximab therapy in colorectal cancer. Cancer Research 66 3992-3995.

Lynch TJ, Bell DW, Sordella R, Gurubhagavatula S, Okimoto RA, Brannigan BW, Harris PL, Haserlat SM, Supko JG, Haluska FG et al. 2004 Activating mutations in the epidermal growth factor receptor underlying responsiveness of non-small-cell lung cancer to gefitinib. New England Journal of Medicine 350 2129-2139.

Massarelli E, Varella-Garcia M, Tang X, Xavier AC, Ozburn NC, Liu DD, Bekele BN, Herbst RS \& Wistuba II 2007 KRAS mutation is an important predictor of resistance to therapy with epidermal growth factor receptor tyrosine kinase inhibitors in non-small cell lung cancer. Clinical Cancer Research 13 2890-2896.

Modlin IM, Moss SF, Chung DC, Jensen RT \& Snyderwine E 2008 Priorities for improving the management of gastroenteropancreatic neuroendocrine tumors. Journal of the National Cancer Institute 100 1282-1289.
Modlin IM, Pavel M, Kidd M \& Gustafsson BI 2010 Review article: somatostatin analogues in the treatment of gastroenteropancreatic neuroendocrine (carcinoid) tumours. Alimentary Pharmacology \& Therapeutics 31 169-188.

Morgan MA, Dolp O \& Reuter CWM 2001 Cell-cycledependent activation of mitogen-activated protein kinase kinase (MEK-1/2) in myeloid leukemia cell lines and induction of growth inhibition and apoptosis by inhibitors of RAS signaling. Blood 97 1823-1834.

Moroni M, Veronese S, Benvenuti S, Marrapese G, SartoreBianchi A, Di Nicolantonio F, Gambacorta M, Siena S \& Bardelli A 2005 Gene copy number for epidermal growth factor receptor (EGFR) and clinical response to antiEGFR treatment in colorectal cancer: a cohort study. Lancet Oncology 6 279-286.

Paez JG, Janne PA, Lee JC, Tracy S, Greulich H, Gabriel S, Herman P, Kaye FJ, Lindeman N, Boggon TJ et al. 2004 EGFR mutations in lung cancer: correlation with clinical response to gefitinib therapy. Science 304 1497-1500.

Pao W, Wang TY, Riely GJ, Miller VA, Pan Q, Ladanyi M, Zakowski MF, Heelan RT, Kris MG \& Varmus HE 2005 KRAS mutations and primary resistance of lung adenocarcinomas to gefitinib or erlotinib. PLoS Medicine 2 57-61.

Papouchado B, Erickson LA, Rohlinger AL, Hobday TJ, Erlichman C, Ames MM \& Lloyd RV 2005 Epidermal growth factor receptor and activated epidermal growth factor receptor expression in gastrointestinal carcinoids and pancreatic endocrine carcinomas. Modern Pathology 18 1329-1335.

Patel YC 1999 Somatostatin and its receptor family. Frontiers in Neuroendocrinology 20 157-198.

Perez EA, Roche PC, Jenkins RB, Reynolds CA, Halling KC, Ingle JN \& Wold LE 2002 HER2 testing in patients with breast cancer: poor correlation between weak positivity by immunohistochemistry and gene amplification by fluorescence in situ hybridization. Mayo Clinic Proceedings 77 148-154.

Sartore-Bianchi A, Moroni M, Veronese S, Carnaghi C, Bajetta E, Luppi G, Sobrero A, Barone C, Cascinu S, Colucci G et al. 2007 Epidermal growth factor receptor gene copy number and clinical outcome of metastatic colorectal cancer treated with panitumumab. Journal of Clinical Oncology 25 3238-3245.

Schnirer II, Yao JC \& Ajani JA 2003 Carcinoid: a comprehensive review. Acta Oncologica 42 672-692.

Wolff AC, Hammond MEH, Schwartz JN, Hagerty KL, Allred DC, Cote RJ, Dowsett M, Fitzgibbons PL, Hanna WM, Langer A et al. 2007 American Society of Clinical Oncology/College of American Pathologists guideline recommendations for human epidermal growth factor receptor 2 testing in breast cancer. Journal of Clinical Oncology 25 118-145. 